\title{
Multimorbidity in chronic disease: impact on health care resources and costs
}

This article was published in the following Dove Press journal:

Risk Management and Healthcare Policy

5 July 2016

Number of times this article has been viewed

\author{
Steven M McPhail ${ }^{1,2}$ \\ 'Centre for Functioning and Health \\ Research, Metro South Health, \\ ${ }^{2}$ Institute of Health and Biomedical \\ Innovation and School of Public \\ Health and Social Work, Queensland \\ University of Technology, Brisbane, \\ QLD, Australia
}

\begin{abstract}
Effective and resource-efficient long-term management of multimorbidity is one of the greatest health-related challenges facing patients, health professionals, and society more broadly. The purpose of this review was to provide a synthesis of literature examining multimorbidity and resource utilization, including implications for cost-effectiveness estimates and resource allocation decision making. In summary, previous literature has reported substantially greater, near exponential, increases in health care costs and resource utilization when additional chronic comorbid conditions are present. Increased health care costs have been linked to elevated rates of primary care and specialist physician occasions of service, medication use, emergency department presentations, and hospital admissions (both frequency of admissions and bed days occupied). There is currently a paucity of cost-effectiveness information for chronic disease interventions originating from patient samples with multimorbidity. The scarcity of robust economic evaluations in the field represents a considerable challenge for resource allocation decision making intended to reduce the burden of multimorbidity in resource-constrained health care systems. Nonetheless, the few cost-effectiveness studies that are available provide valuable insight into the potential positive and cost-effective impact that interventions may have among patients with multiple comorbidities. These studies also highlight some of the pragmatic and methodological challenges underlying the conduct of economic evaluations among people who may have advanced age, frailty, and disadvantageous socioeconomic circumstances, and where long-term follow-up may be required to directly observe sustained and measurable health and quality of life benefits. Research in the field has indicated that the impact of multimorbidity on health care costs and resources will likely differ across health systems, regions, disease combinations, and person-specific factors (including social disadvantage and age), which represent important considerations for health service planning. Important priorities for research include economic evaluations of interventions, services, or health system approaches that can remediate the burden of multimorbidity in safe and cost-effective ways.
\end{abstract}

Keywords: chronic disease, comorbidity, economic, complexity, cost-effectiveness, burden

\section{Background}

Effective and efficient long-term management of multiple comorbid chronic diseases is one of the greatest health-related challenges facing patients, health professionals, and society more broadly who fund health care services. ${ }^{1-6}$ Multimorbidity poses substantial difficulties for health care policy and resource allocation decision making in the presence of imperfect information, aging populations, and increasingly undesirable societal lifestyle characteristics. ${ }^{7-10}$ The complexity associated with management of multimorbidity has a variety of sources. Not the least of these are inconsistencies
Correspondence: Steven M McPhail

Center for Functioning and Health

Research, PO BOX 6053, Buranda, 4I02,

QLD, Australia

Tel +6I 734062266

Fax +6I 734062267

Email steven.mcphail@qut.edu.au 
across research literature in the field beginning at the very foundation of the conceptualization and definition of multimorbidity, but extending throughout observational and interventional studies seeking to describe epidemiological characteristics and investigate potential solutions to alleviate the burden associated with multimorbidity. ${ }^{9,11}$ For the most part, multimorbidity has been defined loosely as the presence of multiple chronic conditions, albeit that no gold standard definition presently exists. ${ }^{9,11}$ Differences have been reported in terms of the number or types of conditions required to be present before a classification of multimorbidity is applied, or in the quantification of the extent of multimorbidity present. ${ }^{11-15}$ As a result, multimorbidity has been measured in a variety of ways. ${ }^{11}$

Approaches to quantifying multimorbidity in studies considering costs and health care resource usage have tended to focus on diagnosis-based indices. ${ }^{1,9,16-19}$ These indices typically include counts of diagnoses with or without a weighting system dependent on the specific index used..$^{1,9,15-19}$ Perhaps the most well-known of these is the Charlson Comorbidities Index and its adaptations. ${ }^{20,21}$ Other approaches include indices derived from medication data, as well as groups of medications or diagnoses groups. ${ }^{15,18}$ For example, the modified Chronic Disease Score uses medications and includes 28 disease categories weighted from prior regression models. ${ }^{22}$

There have been several key conclusions from literature examining the definition and measurement of multimorbidity that have relevance for understanding health care costs and resource utilization. ${ }^{11,13,15,23}$ First, there are inconsistencies in the number and types of diagnoses used to define multimorbidity across measurement approaches. ${ }^{9,11,13,23}$ This is a source of difficulty when comparing resource utilization and health care cost information across studies. Second, there are nuances between the conceptualization of cormorbidity or multimorbidity, in comparison to morbidity burden that includes other health-related factors, or patient complexity that includes non health-related patient-level factors. ${ }^{23}$ For a detailed discussion of the conceptualization of constructs related to multimorbidity, see the review by Valderas et al. ${ }^{23}$ Third, the number of conditions attributed to research participants is likely to be dependent on the data sources and potentially the incentives that may influence whether a comprehensive list of health conditions has been documented. ${ }^{9}$ For example, the incentives for a busy clinician in a primary care general practice setting may substantially differ from the incentives of a data coder in an insurance-claim setting.

Consideration of incentives for data coding is just one of a broader spectrum of data-related issues that are worthy of consideration for health systems internationally as they look to identify opportunities to improve the effectiveness and efficiency of services for people with multimorbidity. This is an area of importance as the use of "big data" analytical approaches to better understand, plan for, and optimize health care resource allocation become an increasingly mainstream activity for health systems internationally. Some other challenges worthy of consideration to improve the richness of routinely recorded information in increasingly digitalized health systems may include enhanced compatibility of digital systems across hospital and community health care interfaces and standardization of approaches to disease classifications that also include potential for quantification of disease severity (rather than simply the presence or absence of a condition) among people with multimorbidity. Despite differences in the definition and measurement of multimorbidity, there is consensus that multimorbidity is a growing concern for health care policy makers trying to provide optimal health care services within resource-constrained environments. ${ }^{6,12,14,24-29}$

Three important and interrelated challenges for contemporary health care policy include the aging nature of population demographics, development of chronic diseases at younger ages, and socioeconomic inequalities in the distribution of multimorbidity and its effects..$^{6,14,25,29,30}$ Older age, undesirable lifestyle factors, and socioeconomic deprivation have been consistently reported to be associated with the development of chronic disease, and in particular, multiple chronic diseases. ${ }^{5,10,14,19,29-32}$ While living to older ages ought to be celebrated, the increasing proportion of older adults in the population, and increasing proportion of younger adults with multimorbidity who will live to advanced ages, has health care policy implications, particularly for the funding of sustainable health care services. ${ }^{6,33-35}$

The demand placed on health services by increasing numbers of older adults with chronic diseases is compounded by earlier onset of chronic disease that is accompanying increasingly sedentary lifestyles and undesirable dietary behaviors. ${ }^{5,10,36-39}$ This earlier onset of chronic disease does not affect all segments of society equally, with the onset of multimorbidity having been estimated to occur 10-15 years earlier among people living in areas classified as being the most socioeconomically deprived in comparison to the least deprived. ${ }^{29}$

There has been substantial investment in public health initiatives and health care system redesign in some countries attempting to reduce the impact of multimorbidity and patient complexity on individuals and societies, particularly in areas where socioeconomic deprivation is prevalent. ${ }^{30,40-42}$ 
For example, in the United Kingdom, health care reforms last decade introduced a pay for performance initiative called the quality and outcomes framework. ${ }^{30,40}$ This initiative provided primary care practices with financial incentives for undertaking specified activities related to the management of chronic disease, including secondary prevention. Some measureable improvements in outcomes for people with multimorbidity and complex health states including older adults and people from socioeconomically deprived areas have been observed, albeit that improvements have been modest and below initial targets. ${ }^{30,40}$ Nonetheless, there is undoubtedly further opportunity to improve the capacity of health systems to effectively and efficiently reduce the burden of multimorbidity on individuals and societies.

There has been an increase in research interest regarding how to best manage chronic disease, and perhaps more recently, a rapid increase in studies investigating multimorbidity. The increasing interest in chronic disease comorbidity and multimorbidity can be demonstrated with a search of the PubMed database for the full calendar years from 1985 to 2014 using the search string:

((multimorbid*) or (multiple comorbid*) or (multiple chronic condition*) or (multiple chronic disease*)).

This search yielded 3,054 hits. The number of hits per calendar year is displayed in Figure 1 (darkest shade). For the purpose of comparison, the total number of citations added to the PubMed (Medline) database over the same period is also displayed in Figure 1 (light shade). There has been steady growth in the total number of citations being added each year. However, there has been rapidly accelerating growth in multimorbidity publications since approximately 2003. It is also noteworthy that approximately 1,000 of these citations were identified from the multiple comorbid* term; likely describing the level of comorbidity in a study sample,

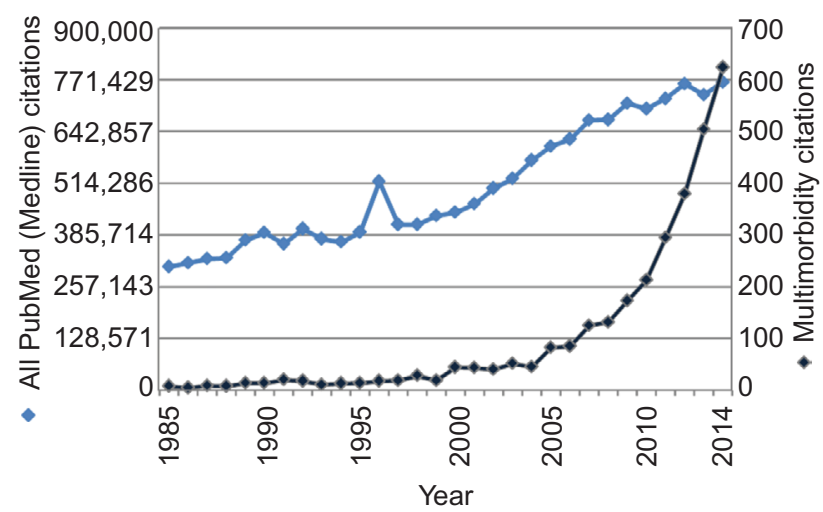

Figure I Number of citations per year for PubMed search for the multimorbidity search string (dark blue) in comparison to number of citations added (light blue). rather than multimorbidity being the focus of the investigation. Repeating this search string without the comorbid* term substantially reduced the number of hits to 1,871 , although the same pattern of rapid recent growth in citations per year was observed (not displayed).

The purpose of the remainder of this review is to provide a synthesis of literature examining multimorbidity and resource utilization, as well as discuss implications of multimorbidity on intervention cost-effectiveness estimates and resource allocation decisions, as well as highlighting some priorities for future research in the field regarding health care resourcing and costs.

\section{Health care costs and resources utilization}

Attributing costs and resource utilization to specific diseases can be complicated by the presence of multiple chronic diseases. Various methodological approaches for inclusion of comorbidities in studies that investigate the cost of an illness have been examined. ${ }^{43-47}$ A key principle outlined in prior literature in this field is that diseases that occur in addition to a disease of interest may be classified in one of four ways (Figure 2). ${ }^{43}$ First, a disease of interest may be caused by another disease. Second, two diseases may be correlated with a causal link. Third, the disease of interest may cause another disease. Fourth, two diseases may have no causal link and have only weak or no significant association. ${ }^{43}$

These differences in the categorization of correlation and causal relationships have been demonstrated to have substantial effect on cost of illness estimates. ${ }^{43}$ In a study investigating the methods for determining the cost of illnesses, Rizzo et $\mathrm{al}^{43}$ concluded that when determining the cost of a particular illness of interest when other chronic diseases may be present in a sample, those comorbidities falling in the second, third, and potentially first aforementioned categories (Figure 2) should be taken into account when modeling disease costs. Although this decision may not always be straightforward, their rationale was supported by analyses of Medical Expenditure Panel Survey data from a very large sample. ${ }^{43}$ In summary, failing to adjust for conditions that are correlated but have no causal relationship (Category 2) may lead to an overestimation of the cost of the illness of interest. On the other hand, failing to adjust for the cost of conditions caused by the condition of interest (Category 3) may lead to an underestimation of the cost of the illness of interest. However, the conceptual rationale for (Category 1) conditions that cause the condition of interest is less clear. It would seem that under some scenarios, no adjustments for the 


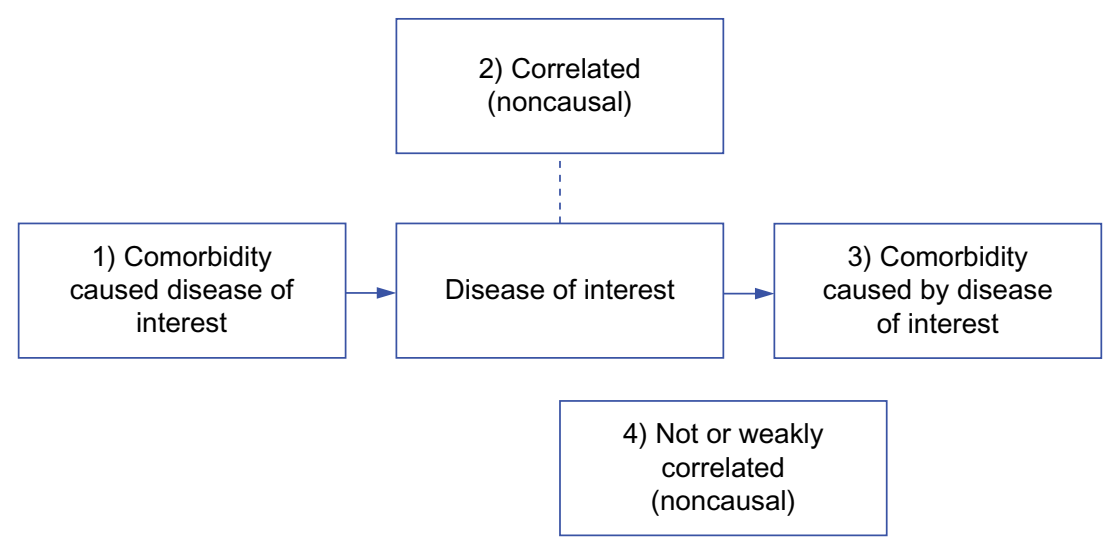

Figure 2 A comorbid condition may I) cause, 2) be correlated without causality, 3) be caused by, or 4) have no causal relationship and no (or weak) correlation with a condition of interest in cost of illness studies.

Category 1 conditions could lead to overestimates of the cost of the illness of interest, ${ }^{48}$ while in other scenarios complete adjustment for the Category 1 condition would lead to an estimate of the cost of illness for cases that were not caused by Category 1 condition, which may also be problematic. ${ }^{43}$ Therefore, the potential adjustment for conditions in a causal relationship with the condition of interest may need to be considered on a case-by-case basis in cost of illness estimates. Appropriate sensitivity analyses may also need to be prepared to examine the potential influence of analytical decisions on the cost of illness estimates when multimorbidity is likely to be present in the population.

Quantifying costs attributable to specific diseases or risk factors is challenging, but potentially useful for understanding the relative burden of each chronic condition. Prior research has indicated that some specific combinations of diseases may be synergistic in terms of their impact on function and quality of life. ${ }^{49-51}$ Although literature in the field is still emerging, it is also likely that some specific combinations of chronic diseases may have a disproportionate impact on health care utilization than simple addition of the respective single disease burdens. ${ }^{43}$ However, there is already consensus that more chronic diseases present are typically associated with greater health care costs. ${ }^{1,9,16-19,43}$

A review conducted by Lehnert et al $^{1}$ examined health care utilization among older adults with multiple chronic conditions in 35 studies. The principal finding was the relationship between additional chronic conditions and health care costs was curve-linear, near exponential. While a large proportion of the included studies originated in the United States $(n=23)$, the remainder of studies were distributed across several regions internationally, adding some weight to the ability of these findings to be generalized. ${ }^{1}$

There is consensus that multimorbidity is associated with substantially higher health care costs, but important further considerations for healthcare policy are the patterns of health service utilization among people with multimorbidity. ${ }^{1,15,19,52,53}$ The weight of evidence investigating the patterns of health resource utilization associated with multimorbidity has reported that multimorbidity is associated with higher levels of utilization across resource types including medications, ${ }^{31,53-57}$ primary care, and outpatient specialist occasions of service, ${ }^{13,14,17,53,58,59}$ as well as emergency department presentations and hospitalizations. ${ }^{19,60-62}$ However, there is considerable variation in the magnitude of increases in resource utilization reported between studies, health systems, and data sources from which study findings were derived.

Studies investigating primary and other ambulatory care have indicated that the occasions of accessing physician services have been consistently higher among people with multiple chronic diseases, even after adjustment for potential confounders like age, sex, and income. ${ }^{13,14,17,53,58,59,63}$ For example, a Canadian study by Rapoport et a ${ }^{63}$ reported $51 \%$ greater use of physician services for each additional chronic disease. It is also noteworthy that people with multimorbidity seem more likely to see a specialist physician for a chronic condition that would usually fall within the scope of a primary care service.$^{59}$ In summary, older adults with multimorbidity have been reported to utilize between two and five times more physician appointments than their peers without chronic conditions. ${ }^{64-66}$

Multiple chronic diseases have also been associated with greater medication usage. Estimates of the amount of additional prescription medications per additional comorbidity have varied widely depending on data sources and study context. ${ }^{31,53-57}$ Fahlman et al ${ }^{54}$ investigated prescription medication usage in the last year of life among Medicare beneficiaries in the United States. They reported that people with five or more comorbidities used an additional eight prescriptions for each additional comorbidity during their last year of 
life. ${ }^{54}$ Moxey et al ${ }^{55}$ investigated costs of medications among the elderly. They concluded that the category of patients with three or more comorbidities utilized prescription medications incurring an average cost 6.6 times greater than peers without comorbidities, and 2.1 times greater than peers with one or two comorbidities. ${ }^{55}$ Similar patterns of medication usage among non-elderly adults with and without multiple chronic conditions have also been reported. ${ }^{31,53}$

Multimorbidity has also been associated with emergency department presentations and hospital admissions. ${ }^{19,60-62,64} \mathrm{~A}$ study by Schneider et $\mathrm{al}^{64}$ among older adults in the United States reported that patients with three or more chronic conditions utilized 25 times more hospital bed-days during 14.6 times more hospital admissions than peers without any chronic conditions. This pattern of positive associations between multimorbidity and hospital resource utilization has been consistently reported across a range of other studies in the field. ${ }^{19,60-62}$ The association between multimorbidity and hospital admissions is also consistent with observations of greater numbers of emergency department presentations, as well readmissions to hospital following discharge, among people who have greater numbers of chronic health conditions. ${ }^{19,61,67}$

The impact of multimorbidity on costs and resource utilization extends beyond insurers and government funding of health care systems to individual patients who directly experience out-of-pocket costs associated with their health care usage. ${ }^{45,66,68-70}$ For example, the out-of-pocket costs are reported as being 2.1 times higher for older adults with multiple chronic conditions than those without multiple chronic conditions. ${ }^{57}$ It is also noteworthy that out-of-pocket costs for people with multimorbidity are increasing at a rate faster than wage growth or broader consumer inflation levels and with great potential to adversely affect the lives of the most vulnerable members of society, particularly those without adequate health insurance coverage or access to universal health care systems. ${ }^{14,36,37,66,71}$

\section{Multimorbidity underrepresented in trial-based economic evaluations}

Trial-based economic evaluations are an invaluable approach for understanding the cost-effectiveness of health interventions. However, cost-effectiveness estimates of health interventions derived from randomized controlled trials may often only include highly selected patient samples. Inclusion and exclusion criteria for clinical trials of physical or mental health interventions may result in underrepresentation of complex patients, including patients with multiple chronic conditions. ${ }^{72-75}$ This selectivity permits rigorous evaluation of the effect of an intervention on a specific condition, under tightly regulated circumstances and sample characteristics, relative to a control or comparator intervention under comparable circumstances and sample characteristics. Conducting economic evaluations derived from clinical trials is worthwhile. However, it is noteworthy that cost-effectiveness estimates derived from patients without multiple chronic conditions receiving a clinical trial intervention may not be generalizable to patients with multiple chronic conditions who receive the same intervention. ${ }^{76-78}$

The lack of cost-effectiveness information available for chronic disease interventions derived from people with multimorbidity is concerning. ${ }^{14}$ A Cochrane systematic review published in April 2012 that examined the effect of primary care and interventions in community settings for people with multiple chronic conditions identified ten trials for inclusion; however, there were no accompanying economic evaluations. ${ }^{14}$ The authors of the review postulated that cost savings were plausible based on some favorable intervention effects related to pharmaceutical use and reductions in chronic disease risk factors, but the cost-effectiveness of interventions were not specifically reported. Studies in the field since the aforementioned Cochrane review have also rarely considered cost-effectiveness estimates. ${ }^{79,80}$ The paucity of cost-effectiveness data to inform allocation decisions in the field of multimorbidity remains a concern. ${ }^{14}$ To highlight the relative scarcity of cost-effectiveness studies in the field of interventions for people with multimorbidity, the following search string was entered into PubMed for January 1, 1985 to September 26, 2015:

((multimorbid*) or (multiple comorbid*) or (multiple chronic condition*) or (multiple chronic disease*)) and ((economic evaluation*) or (cost-effect*))

In summary, the search yielded only 50 citations, of which two articles were describing protocols for studies that have commenced and are intending to include economic evaluations, ${ }^{12,81}$ and four were reports of completed cost-effectiveness studies with a focus on patients with multimorbidity. ${ }^{67,82-84}$ The remainder were not reporting new cost-effectiveness data for chronic disease interventions among people with multimorbidity. This search was not intended to identify all cost-effectiveness studies that may have included patients with more than one chronic condition. Instead, its purpose was to highlight the paucity of cost-effectiveness research in the field in contrast to the increasing number of studies examining multimorbidity that 
have been reported and identified using the same search string without the addition the cost-effectiveness terms (Figure 1).

\section{Cost-effectiveness of multimorbidity interventions}

Despite the relative scarcity of cost-effectiveness studies among interventions targeted at people with multimorbidity, there are several cost-effectiveness studies of multimorbidity that provide valuable insight into the potential impact that interventions may have among patients with comorbidity, as well as some of the challenges underlying the conduct of economic evaluations in the field. A study by Ritzwoller et $\mathrm{l}^{83}$ investigated a 2-year moderate intensity weight-loss intervention delivered to inner-city, high-risk patients with both hypertension and obesity (and other comorbidities) from racial or ethnic minorities (predominantly Black/African American, and Hispanic) as part of a randomized trial. The authors concluded that the additional intervention cost per kilogram of weight loss or per mmHg improvement in blood pressure was higher than the amount that Medicare and Medicaid reimburse physicians for obesity counseling, and higher than products otherwise commercially available. ${ }^{83}$ However, future health benefits and health care costs saved among a high-risk clinical population such as this are likely to be important considerations regarding the cost-effectiveness of the program, but were not within the scope of the assessments and analyses.

Long-term or lifetime modeling of potential attainment of health benefits (and costs) may be required to demonstrate tangible health benefits and large reductions in health service utilization for some multimorbidity interventions..$^{85,86}$ Unfortunately, long-term modeling may also come with untenable levels of uncertainty that preclude meaningful conclusions being drawn. ${ }^{85,86}$ In particular, it may be difficult to determine how long intervention effects from lifestyle behavior change interventions will last.

Katon et a ${ }^{87}$ reported a randomized trial that investigated a collaborative care intervention delivered by physician supervised nurses and primary care physicians targeted at improving depression and physiological parameters among patients with depressive disorders with either diabetes or coronary heart disease. The authors concluded favorable findings regarding the cost per quality-adjusted life years (QALYs) gained from the intervention within the study follow-up period. ${ }^{88}$ However, it is noteworthy that QALYs were not directly measured in this study. Instead, QALYs were estimated using a regression model derived from a prior cohort study among patients with diabetes. ${ }^{88,89}$
This two-step approach of modeling QALYs on the basis of prior research offers pragmatic advantages in terms of being able to estimate QALYs from changes in physiological parameters. ${ }^{88}$ However, the prior model from which the QALY estimates were generated was taken from a sample of people with diabetes, but not necessarily comorbid depression or coronary heart disease. ${ }^{89}$ The impact of estimating QALYs in this way, versus direct measurement from patient self-reports, in their study is uncertain in terms of the accuracy and precision of QALY estimates. This is not a criticism of the investigators, who ought to be commended for their contributions to the field and their transparent analysis and reporting, but rather this demonstrates something of the challenges that exist in producing robust economic evaluations to inform policy and practice.

There are also more general pragmatic challenges regarding the quantification of costs and effects among people with multiple chronic conditions. The aforementioned study by Katon et a ${ }^{88}$ included a 2-year follow-up and demonstrated benefits in physiological parameters that were modeled to estimate QALY gains. ${ }^{89}$ In practice, interventions for some combinations of chronic diseases may require many years of ongoing intervention (and follow-up) among large samples before benefits can be directly observed. ${ }^{90-92}$ For example, a reduction in the rate of stroke or myocardial infarction may not be directly observable within the scope of most research investigations. The probabilistic modeling of future health benefits and economic costs may provide insight into the likelihood of whether interventions may be considered costeffective over longer time horizons in the absence of extensive longitudinal observation. ${ }^{85,86,93}$ However, in the context of finite intervention and observation periods being used as a foundation for probability estimates among multimorbid patients, the duration of intervention effect on risk reduction for inclusion in cost-effectiveness models may have levels of uncertainty that are difficult to quantify.

On the other hand, some interventions for people with multimorbidity may have immediate impacts on healthrelated quality of life that are of sufficient magnitude to justify allocation of resources. ${ }^{82,88}$ However, it is noteworthy that calculating QALYs attributable to an intervention may be complicated among people with multiple health conditions due to both pragmatic considerations as well as habituation effects or "response shift". ${ }^{94,95}$ In this context, response shift refers to internal changes in the way that individuals conceptualize, prioritize, and value their own health states when reporting their health-related quality of life over longitudinal assessment points. This may occur as part of an adaptive or 
self-preserving process that enables people in poor health states with multimorbidity to reconsider how they conceptualize and value their own health state.

There has been a great deal written about people's potential to adapt to poor health-related circumstances over time and potentially maintain positive self-perceptions of their own quality of life..$^{96-98}$ This may generally be considered a favorable adaptation for the individual, but these adaptations have the potential to invalidate QALYs derived from longitudinal health-related quality of life assessments if respondents have systematically altered the way they conceptualize, prioritize, and value aspects of their own health-related quality of life between assessments. ${ }^{94,95,99-101}$ If these adaptations occur in a systematic way in a group of study participants, this may lead to response shift trend that under or overestimates QALYs attributable to an intervention, or potentially even the direction of effect..$^{95,101,102}$ Although methods to adjust for these adaptations have been proposed, the impact of these adaptations (and methods of adjustment) on QALY estimates among people with multimorbidity derived for the purpose of guiding resource allocation decisions is currently unknown. ${ }^{102-105}$

Other pragmatic challenges may include difficulty with the completion of self-reported health-related quality of life instruments by people who may have low levels of health literacy, potential cognitive impairments, poor vision, and other deficits associated with age-related frailty or poor health states. ${ }^{106-109}$ Proxy reporting of health-related quality of life for the purpose of QALY estimates may be justified in some cases. However, proxy reporting is also accompanied by its own set of challenges including determining who the most appropriate proxy is and the perspective from which the proxy should report. ${ }^{110-112}$

\section{Challenges in resources allocation decision making}

The relative scarcity of robust economic evaluations quantifying the cost-effectiveness of interventions for multimorbidity creates challenges for resource allocation decision making. Nonetheless, this does not negate the need for judicious allocation of resources to attempt to stem the burden of multimorbidity internationally, albeit in the presence of imperfect information. Perhaps one of the clear messages arising from both health and economic data pertaining to multimorbidity is that the best course of action may be to prevent the development of multiple chronic diseases at the outset. $1,14,25,38,113,114$

It has been proposed that poorly targeted primary prevention activities typically increase costs, whereas appropriately targeted primary (or secondary) prevention activities are more likely to be cost-effective. ${ }^{115}$ While this is likely to be true in many cases, exceptions may include brief and relatively inexpensive interventions (like low-cost vaccines) that may be cost-effective in preventing severe long-lasting conditions, particularly when there is potential for population coverage that can all but eliminate the presence of a condition within an entire population and yield long-term benefits. Perhaps there is no better case in point than polio vaccination that, from a cost-effectiveness point of view, may be considered a dominant strategy (in that it is both effective and cost saving from society's perspective). ${ }^{116}$ However, this is in contrast to most primary prevention activities that have potential to prevent chronic disease but carry a net financial cost, which may or may not exceed willingness to pay thresholds for agencies that fund primary prevention activities. ${ }^{116,117}$

The curve-linear, near-exponential cost of health care associated with additional chronic diseases ${ }^{1}$ may indicate that cost-effective appropriately targeted secondary prevention interventions should be considered an important line of defense for reducing the burden of multimorbidity in a cost-efficient way. ${ }^{118-121}$ This may be a somewhat idealist notion in the midst of current secular demographic trends. Nonetheless, it is plausible that secondary prevention may have some efficiency gains (perhaps in comparison to primary prevention) when it can be targeted to priority clinical groups at very high risk of subsequent negative health events and disease combinations. ${ }^{71,79,118-120,122}$ This may result in greater resource utilization avoidance per effective preventative intervention delivered in comparison to broader primary prevention interventions that may have larger number needed to treat or number needed to screen values. ${ }^{123-127}$

It is also noteworthy that the intervention studies and economic data that have been reported to date indicate that interventions for multimorbidity have the potential to be effective and cost-efficient, ${ }^{67,84}$ even in the absence of robust economic evaluations. For example, studies investigating various potential integrated care models targeting specific risk factors among patients with multimorbidity have generally reported positive findings. ${ }^{14,79,84}$ The additional per-patient labor costs, potentially from nursing or allied health professionals, for appropriately coordinated care for patients with multimorbidity may not be particularly expensive in comparison to usual care approaches that are less integrated and less effective. ${ }^{14,67,79,84}$ Similarly, interventions that promote chronic disease self-management and beneficial lifestyle changes have also not been associated with particularly large per-person intervention costs, even when costs of supports 
provided using contemporary communication technologies that may enhance the longevity of behavior change interventions are taken into account. ${ }^{2,67,114,128}$

An important risk when considering the potential allocation of resources for society is the risk of cost-shifting versus true efficiency gains in the context of care for people with multimorbidity. Effective models of primary and community care that reduce demand on hospital and specialty services have great potential to generate a net reduction in health care resource utilization, particularly due to high costs associated with hospital admissions. ${ }^{8,53,62}$ An approach that leads to a net reduction in health care resource usage is likely to be embraced in health systems where there is a single health care funder perspective that drives resource allocation decisions; this may include nationalized health services. However, approaches that lead to a net reduction in health care resource utilization may not always be considered favorable for each individual segment of the health system when funding of the health system is fragmented, and incentives do not adequately reward judicious resource allocation decisions within each affected segment of the system. ${ }^{129-132}$

Although an intervention for multimorbidity may lead to a net reduction in costs, a whole-of-system approach may be required to make appropriate resource allocation decisions when intervention costs and resource savings affect different segments of the health care system. ${ }^{130-133}$ The Australian health care system is an interesting case in point where the funding of health care is fragmented. ${ }^{134}$ In the Australian system, primary care and medications are largely funded by the Australian federal government through taxation (acting as national insurance scheme), whereas public hospitals are coordinated in local hospital and health services that receive funding via individual state governments (albeit with federal government contributions). One of the greatest benefits of high-quality primary care and community services for chronic diseases may be a reduction in hospital presentations or lengths of stay in hospital. ${ }^{14,79}$ However, in the presence of a fragmented funding model where benefits yielded in secondary or tertiary care require greater investment in of resources in primary care, a policy decision to allocate a higher proportion of a finite resource pool to primary health care would require consideration of health benefits to patients and the health care system more broadly.

There may be benefits for health care reforms and implementation of coordinated care strategies for people with multimorbidity and complex care needs among systems with less fragmentation, such as the United Kingdom's National Health Service (and perhaps somewhat similar nationalized health services in the Netherlands and New Zealand). In these health systems, patients tend to register with general practices in community-based primary care settings that act as gateways and coordination points for referrals to more specialized care. ${ }^{135}$ Although this approach is not unique to nationalized health services, a single health care funding agent (eg, a federal government) may solidify an incentive for efficient coordinated care using this approach without any incentive for adverse cost-shifting to segments of the system that are funded by another funding agent (eg, provincial or state governments, private health insurers, or out-of-pocket cost's for patient). In this regard, a survey of the coordination of care from the perspective of patients in eleven countries indicated that the United Kingdom's National Health Service had many favorable attributes in coordination of care that promote efficiency. ${ }^{135}$ This typically included a higher probability of test results being available at the time of appointments or fewer duplicate tests ordered, higher probability of doctors being informed of their patients' hospital and surgical care, and fewer gaps in the planning of discharge care following hospitalization in comparison to systems with fragmented or competing funding agents. ${ }^{135}$ These benefits may not be solely attributable to the structure of the health system, as staff training, health service culture, incumbent processes, and other factors are likely to have played a role, but it is likely that the structure of health systems will undoubtedly contribute (for better or worse) to the efficiency in resource usage and effectiveness of care provided for people with multimorbidity.

A particularly difficult and potentially contentious circumstance for consideration in any discussion of resource allocation decision making is that related to end-of-life care. ${ }^{136,137}$ There is clear evidence that people with many health conditions utilize substantially greater health care resources than those with fewer or no comorbid health conditions during the last year of their life..$^{54,138,139} \mathrm{~A}$ key point for consideration when it comes to practical policy and clinical practice considerations regarding end-of-life care is that it may be very difficult to determine when a person with multiple chronic conditions is about to experience negative health events that result in mortality. A person with multimorbidity may experience many nonterminal acute events or exacerbation of symptoms over the last decades of their life for which contemporary health care interventions would extend the quantity and quality of their life in a meaningful (and potentially cost-efficient) way. As a result, it is very difficult to make resource allocation decisions at a universal policy level when it comes to end-of-life care for people 
with multimorbidity. Frost et al ${ }^{139}$ reported a systematic review that considered both patient and health care professional factors associated with decision making in end-of-life care. They concluded that patient age and comorbidities present were influential factors for both patients and health professionals during health care decision making in times of critical illness. ${ }^{139}$ Further research and open discussion about end-of-life decision making among critically ill people with multimorbidity is warranted.

\section{Priorities for research}

Opportunities for research in the field of multimorbidity abound. However, this discussion will be limited to a few priorities for research regarding health care costs, costeffectiveness of interventions or models of care, and resource allocation decision making. While the identification of some research priorities is intended to stimulate further discussion or debate, this is by no means intended as an exhaustive list of research priorities in the field.

The impact of multimorbidity on health care costs and resources will likely differ greatly across health systems, geographical regions, disease combinations, and person-specific factors (including social disadvantage and age). 1,9,37,46,53,63,69 Most studies exploring the impact of multimorbidity on health care costs and resources to date have been generated from relatively few health systems and regions. Investigations to understand the impact of multimorbidity on health care utilization in other health systems and regions would be useful for informing policy and practice in those (and similar) systems. Similarly, multimorbidity intervention studies to date have tended to focus on relatively few disease combinations, or chronic disease risk factors, with limited consideration of the potential impact of intervening in concordant versus discordant disease combinations. ${ }^{12,14,82,88,91,114,140,141}$

There is potential opportunity for further investigations to understand the cost effectiveness of implementing what has been termed "minimally disruptive medicine" approaches for people with multimorbidity at a health service level. ${ }^{142,143}$ Minimally disruptive medicine seeks to address a patient's key health concerns with minimally disruptive interventions that are least likely to overwhelm patients who may have large burdens of disease. An underpinning principle is that a minimally disruptive intervention may have a higher chance of being adhered to, and therefore more effective than prescription of a broader range of interventions that have a lower chance of being adhered to due to a greater burden on the patient. ${ }^{142,143}$ Promoting minimally disruptive medicine may be a cost-effective system-level approach to providing cost-effective care for patients with multimorbidity. This is in contrast to promoting many complex, burdensome, and potentially expensive interventions that may deliver diminishing returns, particularly if they are not being adhered to by patients who have substantial cumulative complexity.

The cumulative complexity associated with multimorbidity has been conceptualized in terms of how clinical and social factors accumulate and interact to complicate patient care in through an imbalance between a patient's "workload" and their "capacity" to manage that workload. ${ }^{143}$ When the demand on a patient exceeds their capacity to manage, there may be a higher likelihood of nonadherence with disease management recommendations contributing to greater morbidity or mortality. In this context, patient workload may include treatment, self-care demands, and other general life demands, while patient capacity refers to a patient's ability to cope with these demands. ${ }^{143}$ A patient's capacity may be impacted by their functional abilities, financial resources, health literacy, and other factors. People with multimorbidity may be prone to unfavorable imbalances regarding their ability to meet the demands of managing their health conditions. However, at the present time, there is a scarcity of research investigating the cost-effectiveness of specific minimally disruptive medicine approaches among patients with multimorbidity and this remains a priority for further research.

It is likely that particular combinations of concordant diseases (and chronic disease risk factors) will offer greater opportunities for cost-effective interventions to improve health and reduce health care costs than others. ${ }^{141}$ This is particularly true if a single intervention may be able to have a positive impact on several of the diseases within a common disease cluster. For example, physical activity promoting interventions suitable for people with multimorbidity may be cost-effective for mitigating risks associated with the cluster of conditions represented in metabolic syndrome. Furthermore, investigations to understand the impact of multimorbidity on non-chronic disease-related health system interactions are also worthy of investigation. For example, a greater understanding of the impacts of multimorbidity on acute trauma management and rehabilitation may identify opportunities for enhancing the quality, safety, and efficiency of health care services for people with multimorbidity who have sustained trauma.

Economic evaluations, and cost-effectiveness studies in particular, investigating health care interventions and models of care among people with multimorbidity will provide 
valuable information to inform resource allocation policy and clinical models of care. This includes interventions or models of care specifically targeted to patient populations with multiple chronic conditions, particularly those whereby the intervention can have a sustained impact on risk factors linked with future negative (and costly) health events. Costeffectiveness studies targeting combinations of conditions that have been reported to have the greatest burden (on health and health care costs for society) may have the greatest scope for improving reducing costs where interventions demonstrate effectiveness among people with multimorbidity.

However, there is also a more general requirement to consider the cost-effectiveness of single-disease interventions with data that is inclusive of patients with comorbidities that are most frequently observed alongside the target condition. Clinical trial samples representative of clinical practice populations are likely to enhance the robustness of economic evaluation findings for application in clinical practice settings. ${ }^{25,72,73}$ This is in contrast to economic evaluations derived from studies where complex patients with multimorbidity or advanced age are excluded by design or underrepresented due to pragmatic factors.

Finally, health services research that quantifies the effects of resource allocation decisions on the health of patients and health care costs at a systems level may be among the most important and influential research that can occur in the field of multimorbidity. Health care policy decisions are usually made under conditions of uncertainty, whether the level of uncertainty is known or not. However, robust evaluation of the implementation of new interventions or alternative models of care for people with multimorbidity will likely offer valuable insight into the cost-effectiveness of interventions beyond that which can be derived from conventional randomized controlled trials. The field of implementation science has made very good advancements in recent decades and has great potential for further application in the context of interventions and models of care for people with multimorbidity and complex health care requirements. ${ }^{144,145}$

\section{Acknowledgment}

SMM is supported by a National Health and Medical Research Council (of Australia) fellowship (number 1090440).

\section{Disclosure}

The author reports no conflicts of interest in this work.

\section{References}

1. Lehnert T, Heider D, Leicht H, et al. Review: health care utilization and costs of elderly persons with multiple chronic conditions. Med Care Res Rev. 2011;68(4):387-420.
2. Barlow J, Wright C, Sheasby J, Turner A, Hainsworth J. Self-management approaches for people with chronic conditions: a review. Patient Educ Couns. 2002;48(2):177-187.

3. Boyd CM, Darer J, Boult C, Fried LP, Boult L, Wu AW. Clinical practice guidelines and quality of care for older patients with multiple comorbid diseases: implications for pay for performance. JAMA. 2005;294(6):716-724.

4. Weingarten SR, Henning JM, Badamgarav E, et al. Interventions used in disease management programmes for patients with chronic illness which ones work? Meta-analysis of published reports. BMJ. 2002;325(7370):925.

5. McPhail SM, Schippers M, Marshall AL, Waite M, Kuipers P. Perceived barriers and facilitators to increasing physical activity among people with musculoskeletal disorders: a qualitative investigation to inform intervention development. Clin Interv Aging. 2014;9:2113-2122.

6. Onder G, Palmer K, Navickas R, et al. Time to face the challenge of multimorbidity. A European perspective from the joint action on chronic diseases and promoting healthy ageing across the life cycle (JA-CHRODIS). Eur J Intern Med. 2015;26(3):157-159.

7. Wolff JL, Starfield B, Anderson G. Prevalence, expenditures, and complications of multiple chronic conditions in the elderly. Arch Intern Med. 2002;162(20):2269-2276.

8. Brown RS, Peikes D, Peterson G, Schore J, Razafindrakoto CM. Six features of Medicare coordinated care demonstration programs that cut hospital admissions of high-risk patients. Health Aff. 2012; 31(6):1156-1166.

9. Wittenberg R. The challenge of measuring multi-morbidity and its costs. Isr J Health Policy Res. 2015;4:1.

10. McPhail SM, Schippers M, Marshall AL. Age, physical inactivity, obesity, health conditions, and health-related quality of life among patients receiving conservative management for musculoskeletal disorders. Clin Interv Aging. 2014;9:1069-1080.

11. Lefèvre T, d'Ivernois JF, De Andrade V, Crozet C, Lombrail P, Gagnayre R. What do we mean by multimorbidity? An analysis of the literature on multimorbidity measures, associated factors, and impact on health services organization. Rev Epidemiol Sante Publique. 2014;62(5):305-314.

12. Damery S, Flanagan S, Combes G. The effectiveness of interventions to achieve co-ordinated multidisciplinary care and reduce hospital use for people with chronic diseases: study protocol for a systematic review of reviews. Syst Rev. 2015;4:64.

13. Huntley AL, Johnson R, Purdy S, Valderas JM, Salisbury C. Measures of multimorbidity and morbidity burden for use in primary care and community settings: a systematic review and guide. Ann Fam Med. 2012;10(2):134-141.

14. Smith SM, Soubhi H, Fortin M, Hudon C, O'Dowd T. Managing patients with multimorbidity: systematic review of interventions in primary care and community settings. BMJ. 2012;345:e5205.

15. Yurkovich M, Avina-Zubieta JA, Thomas J, Gorenchtein M, Lacaille D. A systematic review identifies valid comorbidity indices derived from administrative health data. J Clin Epidemiol. 2015;68(1):3-14.

16. Charlson M, Charlson RE, Briggs W, Hollenberg J. Can disease management target patients most likely to generate high costs? The impact of comorbidity. J Gen Intern Med. 2007;22(4):464-469.

17. Charlson ME, Charlson RE, Peterson JC, Marinopoulos SS, Briggs WM, Hollenberg JP. The Charlson comorbidity index is adapted to predict costs of chronic disease in primary care patients. J Clin Epidemiol. 2008;61(12):1234-1240.

18. Perkins AJ, Kroenke K, Unützer J, et al. Common comorbidity scales were similar in their ability to predict health care costs and mortality. J Clin Epidemiol. 2004;57(10):1040-1048.

19. Zulman DM, Chee CP, Wagner TH, et al. Multimorbidity and healthcare utilisation among high-cost patients in the US Veterans Affairs Health Care System. BMJ Open. 2015;5(4):e007771.

20. Charlson ME, Pompei P, Ales KL, MacKenzie CR. A new method of classifying prognostic comorbidity in longitudinal studies: development and validation. J Chronic Dis. 1987;40(5):373-383. 
21. Sundararajan V, Henderson T, Perry C, Muggivan A, Quan H, Ghali WA. New ICD-10 version of the Charlson comorbidity index predicted in-hospital mortality. J Clin Epidemiol. 2004;57(12): $1288-1294$.

22. Clark DO, Korff MV, Saunders K, Baluch WM, Simon GE. A chronic disease score with empirically derived weights. Med Care. 1995;33(8):783-795.

23. Valderas JM, Starfield B, Sibbald B, Salisbury C, Roland M. Defining comorbidity: implications for understanding health and health services Ann Fam Med. 2009;7(4):357-363.

24. Calderón-Larrañaga A, Abad-Díez JM, Gimeno-Feliu LA, et al. Global health care use by patients with type-2 diabetes: does the type of comorbidity matter? Eur J Intern Med. 2015;26(3):203-210.

25. Bernabeu-Wittel M, Alonso-Coello P, Rico-Blázquez M, Rotaeche del Campo R, Sánchez Gómez S, Casariego Vales E. Development of clinical practice guidelines for patients with comorbidity and multiple diseases. Rev Clín Esp. 2014;214(6):328-335.

26. Fortin M, Stewart M, Poitras ME, Almirall J, Maddocks H. A systematic review of prevalence studies on multimorbidity: toward a more uniform methodology. Ann Fam Med. 2012;10(2):142-151.

27. Moussavi S, Chatterji S, Verdes E, Tandon A, Patel V, Ustun B. Depression, chronic diseases, and decrements in health: results from the World Health Surveys. Lancet. 2007;370(9590):851-858.

28. El-Atem NA, Wojcik K, Horsfall L, et al. Patterns of service utilisation within Australian hepatology clinics: high prevalence of advanced liver disease. Intern Med J. 2016;46(4):420-426.

29. Barnett K, Mercer SW, Norbury M, Watt G, Wyke S, Guthrie B. Epidemiology of multimorbidity and implications for health care, research, and medical education: a cross-sectional study. Lancet. 2012;380(9836):37-43.

30. Dixon A, Khachatryan A, Gilmour S. Does general practice reduce health inequalities? Analysis of quality and outcomes framework data. Eur J Public Health. 2012;22(1):9-13.

31. Mueller C, Schur C, O'Connell J. Prescription drug spending: the impact of age and chronic disease status. Am J Public Health. 1997;87(10):1626-1629.

32. Sloane PD, Oudenhoven MD, Broyles I, McNabney M. Challenges to cost-effective care of older adults with multiple chronic conditions: perspectives of Program of All-Inclusive Care for the Elderly medical directors. J Am Geriatr Soc. 2014;62(3):564-565.

33. Bodenheimer T, Chen E, Bennett HD. Confronting the growing burden of chronic disease: can the U.S. health care workforce do the job? Health Aff. 2009;28(1):64-74.

34. Heidenreich PA, Trogdon JG, Khavjou OA, et al. Forecasting the future of cardiovascular disease in the United States: a policy statement from the American Heart Association. Circulation. 2011;123(8): 933-944.

35. Wang YC, McPherson K, Marsh T, Gortmaker SL, Brown M. Health and economic burden of the projected obesity trends in the USA and the UK. Lancet. 2011;378(9793):815-825.

36. Fox MH, Reichard A. Disability, health, and multiple chronic conditions among people eligible for both Medicare and Medicaid, 2005-2010. Prev Chronic Dis. 2013;10:E157.

37. Lawson KD, Mercer SW, Wyke S, et al. Double trouble: the impact of multimorbidity and deprivation on preference-weighted health related quality of life a cross sectional analysis of the Scottish Health Survey. Int J Equity Health. 2013;12:67.

38. Lim SS, Vos T, Flaxman AD, et al. A comparative risk assessment of burden of disease and injury attributable to 67 risk factors and risk factor clusters in 21 regions, 1990-2010: a systematic analysis for the Global Burden of Disease Study 2010. Lancet. 2012;380(9859):2224-2260.

39. McPhail S, Schippers M. An evolving perspective on physical activity counselling by medical professionals. BMC Fam Pract. 2012;13(1):31

40. Dixon A, Khachatryan A, Wallace A, Peckham S, Boyce T, Gillam S The quality and outcomes framework (QOF): does it reduce health inequalities. Final report. London, UK: NIHR; 2010.
41. Tinetti ME, Fried TR, Boyd CM. Designing health care for the most common chronic condition - multimorbidity. JAMA. 2012;307(23):2493-2494.

42. Salisbury C. Multimorbidity: redesigning health care for people who use it. Lancet. 2012;380(9836):7-9.

43. Rizzo JA, Chen J, Gunnarsson CL, Naim A, Lofland JH. Adjusting for comorbidities in cost of illness studies. J Med Econ. 2015;18(1):12-28.

44. Bohensky MA, Ademi Z, deSteiger R, et al. Quantifying the excess cost and resource utilisation for patients with complications associated with elective knee arthroscopy: a retrospective cohort study. Knee. 2014;21(2):491-496.

45. Crystal S, Johnson RW, Harman J, Sambamoorthi U, Kumar R. Outof-pocket health care costs among older Americans. J Gerontol B Psychol Sci Soc Sci. 2000;55(1):S51-S62.

46. Karve S, Candrilli S, Kappelman MD, Tolleson-Rinehart S, Tennis P, Andrews E. Healthcare utilization and comorbidity burden among children and young adults in the United States with systemic lupus erythematosus or inflammatory bowel disease. $J$ Pediatr. 2012;161(4):662-670.e662.

47. Lee DW, Meyer JW, Clouse J. Implications of controlling for comorbid conditions in cost-of-illness estimates: a case study of osteoarthritis from a managed care system perspective. Value Health. 2001;4(4): 329-334.

48. American Diabetes Association. Economic costs of diabetes in the U.S. in 2007. Diabetes Care. 2008;31(3):596-615.

49. Hunger M, Thorand B, Schunk M, et al. Multimorbidity and healthrelated quality of life in the older population: results from the German KORA-age study. Health Qual Life Outcomes. 2011;9(1):1-10.

50. Marventano S, Ayala A, Gonzalez N, Rodríguez-Blázquez C, GarciaGutierrez S, Forjaz MJ. Multimorbidity and functional status in community-dwelling older adults. Eur J Intern Med. 2014;25(7):610-616.

51. Tyack Z, Frakes KA, Barnett A, Cornwell P, Kuys S, McPhail S. Predictors of health-related quality of life in people with a complex chronic disease including multimorbidity: a longitudinal cohort study. Qual Life Res. 2016. Epub April 5, 2016.

52. Andrews G, Henderson S, Hall W. Prevalence, comorbidity, disability and service utilisation overview of the Australian National Mental Health Survey. Br J Psychiatry. 2001;178(2):145-153.

53. Hopman P, Heins MJ, Rijken M, Schellevis FG. Health care utilization of patients with multiple chronic diseases in The Netherlands: Differences and underlying factors. Eur J Intern Med. 2015;26(3): 190-196.

54. Fahlman C, Lynn J, Doberman D, Gabel J, Finch M. Prescription drug spending for Medicare+ Choice beneficiaries in the last year of life. J Palliat Med. 2006;9(4):884-893.

55. Moxey ED, O’Connor JP, Novielli KD, Teutsch S, Nash DB. Prescription drug use in the elderly: a descriptive analysis. Health Care Financ Rev. 2002;24(4):127-141.

56. Ramage-Morin PL. Medication use among senior Canadians. Health Rep. 2009;20(1):37-44.

57. Rogowski J, Lillard LA, Kington R. The financial burden of prescription drug use among elderly persons. Gerontologist. 1997;37(4):475-482.

58. Landis SE, Gaynes BN, Morrissey JP, Vinson N, Ellis AR, Domino ME. Generalist care managers for the treatment of depressed medicaid patients in North Carolina: a pilot study. BMC Fam Pract. 2007;8:7.

59. Starfield B, Lemke KW, Bernhardt T, Foldes SS, Forrest CB, Weiner JP. Comorbidity: implications for the importance of primary care in "case" management. Ann Fam Med. 2003;1(1):8-14.

60. Chan DK, Chong R, Basilikas J, Mathie M, Hung WT. Survey of major chronic illnesses and hospital admissions via the emergency department in a randomized older population in Randwick, Australia. Emerg Med. 2002;14(4):387-392.

61. Chu LW, Pei CK. Risk factors for early emergency hospital readmission in elderly medical patients. Gerontology. 1999;45(4):220-226.

62. Condelius A, Edberg AK, Jakobsson U, Hallberg IR. Hospital admissions among people $65+$ related to multimorbidity, municipal and outpatient care. Arch Gerontol Geriatr. 2008;46(1):41-55. 
63. Rapoport J, Jacobs P, Bell NR, Klarenbach S. Refining the measurement of the economic burden of chronic diseases in Canada. Chronic Dis Can. 2004;25(1):13-21.

64. Schneider KM, O’Donnell BE, Dean D. Prevalence of multiple chronic conditions in the United States' Medicare population. Health Qual Life Outcomes. 2009;7(82):82.

65. Xakellis GC. Are patients who use a generalist physician healthier than those who seek specialty care directly? Fam Med. 2005;37(10): 719-726.

66. Paez KA, Zhao L, Hwang W. Rising out-of-pocket spending for chronic conditions: a ten-year trend. Health Aff. 2009;28(1):15-25.

67. Graves N, Courtney M, Edwards H, Chang A, Parker A, Finlayson K. Cost-effectiveness of an intervention to reduce emergency readmissions to hospital among older patients. PLoS One. 2009;4(10): e7455.

68. Hwang W, Weller W, Ireys H, Anderson G. Out-of-pocket medical spending for care of chronic conditions. Health Aff. 2001;20(6): 267-278.

69. Schoen C, Osborn R, Squires D, Doty MM, Pierson R, Applebaum S. How health insurance design affects access to care and costs, by income, in eleven countries. Health Aff. 2010;29(12):2323-2334.

70. Schoenberg NE, Kim H, Edwards W, Fleming ST. Burden of common multiple-morbidity constellations on out-of-pocket medical expenditures among older adults. Gerontologist. 2007;47(4):423-437.

71. O’Toole J, Hambly R, Cox AM, O'Shea B, Darker C. Methadonemaintained patients in primary care have higher rates of chronic disease and multimorbidity, and use health services more intensively than matched controls. Eur J Gen Pract. 2014;20(4):275-280.

72. Hordijk-Trion M, Lenzen M, Wijns W, et al. Patients enrolled in coronary intervention trials are not representative of patients in clinical practice: results from the Euro Heart Survey on Coronary Revascularization. Eur Heart J. 2006;27(6):671-678.

73. Zimmerman M, Mattia JI, Posternak MA. Are subjects in pharmacological treatment trials of depression representative of patients in routine clinical practice? Am J Psychiatry. 2002;159(3):469-473.

74. Masoudi FA, Havranek EP, Wolfe P, et al. Most hospitalized older persons do not meet the enrollment criteria for clinical trials in heart failure. Am Heart J. 2003;146(2):250-257.

75. Cherubini A, Signore SD, Ouslander J, Semla T, Michel JP. Fighting against age discrimination in clinical trials. JAm Geriatr Soc. 2010;58(9): 1791-1796.

76. Drummond MF, Davies L. Economic analysis alongside clinical trials. Revisiting the methodological issues. Int JTechnol Assess Health Care. 1991;7(4):561-573.

77. O'brien B. Economic evaluation of pharmaceuticals. Frankenstein's monster or vampire of trials? Med Care. 1996;34(12 Suppl): DS99-DS108.

78. Ramsey S, Willke R, Briggs A, et al. Good research practices for costeffectiveness analysis alongside clinical trials: the ISPOR RCT-CEA task force report. Value health. 2005;8(5):521-533.

79. Coventry P, Lovell K, Dickens C, et al. Integrated primary care for patients with mental and physical multimorbidity: cluster randomised controlled trial of collaborative care for patients with depression comorbid with diabetes or cardiovascular disease. BMJ. 2015;350

80. Jäger C, Freund T, Steinhäuser J, Joos S, Wensing M, Szecsenyi J. A tailored implementation intervention to implement recommendations addressing polypharmacy in multimorbid patients: study protocol of a cluster randomized controlled trial. Trials. 2013;14(1):420.

81. Bozorgmehr K, Szecsenyi J, Ose D, et al. Practice network-based care management for patients with type 2 diabetes and multiple comorbidities (GEDIMAplus): study protocol for a randomized controlled trial. Trials. 2014;15:243.

82. Hsieh HM, Gu SM, Shin SJ, Kao HY, Lin YC, Chiu HC. Costeffectiveness of a diabetes pay-for-performance program in diabetes patients with multiple chronic conditions. PLoS One. 2015;10(7): e0133163.
83. Ritzwoller DP, Glasgow RE, Sukhanova AY, et al. Economic analyses of the Be Fit Be Well program: a weight loss program for community health centers. $J$ Gen Intern Med. 2013;28(12):1581-1588.

84. Vila A, Villegas E, Cruanyes J, et al. Cost-effectiveness of a Barcelona home care program for individuals with multimorbidity. J Am Geriatr Soc. 2015;63(5):1017-1024.

85. Drummond MF, McGuire A. Economic Evaluation in Health Care: Merging Theory with Practice. New York, NY: Oxford University Press; 2001.

86. Weinstein MC, O'Brien B, Hornberger J, et al. Principles of good practice for decision analytic modeling in health-care evaluation: report of the ISPOR task force on good research practices - modeling studies. Value Health. 2003;6(1):9-17.

87. Katon WJ, Lin EHB, Von Korff M, et al. Collaborative care for patients with depression and chronic illnesses. $N$ Engl J Med. 2010;363(27):2611-2620.

88. Katon W, Russo J, Lin EH, et al. Cost-effectiveness of a multicondition collaborative care intervention: a randomized controlled trial. Arch GenPsychiatry. 2012;69(5):506-514.

89. Schmittdiel J, Vijan S, Fireman B, Lafata JE, Oestreicher N, Selby JV. Predicted quality-adjusted life years as a composite measure of the clinical value of diabetes risk factor control. Med Care. 2007;45(4): 315-321.

90. Lindström J, Peltonen M, Eriksson J, et al. Improved lifestyle and decreased diabetes risk over 13 years: long-term follow-up of the randomised Finnish Diabetes Prevention Study (DPS). Diabetologia. 2013;56(2):284-293.

91. Li G, Zhang P, Wang J, et al. The long-term effect of lifestyle interventions to prevent diabetes in the China Da Qing Diabetes Prevention Study: a 20-year follow-up study. Lancet. 2008;371(9626):1783-1789.

92. DPPR Group. Long-term effects of lifestyle intervention or metformin on diabetes development and microvascular complications over 15-year follow-up: the Diabetes Prevention Program Outcomes Study. Lancet Diabetes Endocrinol. 2015;3(11):866-875.

93. Tosteson A, Jönsson B, Grima D, O’Brien B, Black D, Adachi J. Challenges for model-based economic evaluations of postmenopausal osteoporosis interventions. Osteopor Int. 2001;12(10):849-857.

94. Sprangers MA, Schwartz CE. Integrating response shift into healthrelated quality of life research: a theoretical model. Soc Sci Med. 1999;48(11):1507-1515.

95. McPhail S, Haines T. The response shift phenomenon in clinical trials. J Clin Res Best Pract. 2010;6(2):1-8.

96. Groot W. Adaptation and scale of reference bias in self-assessments of quality of life. J Health Econ. 2000;19(3):403-420.

97. Menzel P, Dolan P, Richardson J, Olsen JA. The role of adaptation to disability and disease in health state valuation: a preliminary normative analysis. Soc Sci Med. 2002;55(12):2149-2158.

98. Post PN, Stiggelbout AM, Wakker PP. The utility of health states after stroke: a systematic review of the literature. Stroke. 2001;32(6): 1425-1429.

99. McPhail S, Comans T, Haines T. Evidence of disagreement between patient-perceived change and conventional longitudinal evaluation of change in health-related quality of life among older adults. Clin Rehabil. 2010;24(11):1036-1044.

100. Howard GS, Dailey PR. Response-shift bias: a source of contamination of self-report measures. J Appl Psychol. 1979;64(2):144.

101. Daltroy LH, Larson MG, Eaton HM, Phillips CB, Liang MH. Discrepancies between self-reported and observed physical function in the elderly: the influence of response shift and other factors. Soc Sci Med. 1999;48(11):1549-1561.

102. McPhail S, Haines T. Response shift, recall bias and their effect on measuring change in health-related quality of life amongst older hospital patients. Health Qual Life Outcomes. 2010;8:65.

103. Schwartz CE, Sprangers MA. Methodological approaches for assessing response shift in longitudinal health-related quality-of-life research. Soc Sci Med. 1999;48(11):1531-1548. 
104. Oort FJ. Using structural equation modeling to detect response shifts and true change. Qual Life Res. 2005;14(3):587-598.

105. Ahmed S, Mayo NE, Wood-Dauphinee S, Hanley JA, Cohen SR. The structural equation modeling technique did not show a response shift, contrary to the results of the then test and the individualized approaches. J Clin Epidemiol. 2005;58(11):1125-1133.

106. Snyder C, Aaronson N, Choucair A, et al. Implementing patientreported outcomes assessment in clinical practice: a review of the options and considerations. Qual Life Res. 2012;21(8):1305-1314.

107. Hickey A, Barker M, McGee H, O’Boyle C. Measuring health-related quality of life in older patient populations. Pharmacoeconomics. 2005;23(10):971-993.

108. Logsdon RG, Gibbons LE, McCurry SM, Teri L. Assessing quality of life in older adults with cognitive impairment. Psychosom Med. 2002;64(3):510-519.

109. McPhail S, Beller E, Haines T. Reference bias: presentation of extreme health states prior to EQ-VAS improves health-related quality of life scores. A randomised cross-over trial. Health Qual Life Outcomes. 2010;8(1):146.

110. Sneeuw KC, Sprangers MA, Aaronson NK. The role of health care providers and significant others in evaluating the quality of life of patients with chronic disease. J Clin Epidemiol. 2002;55(11):1130-1143.

111. McPhail S, Beller E, Haines T. Two perspectives of proxy reporting of health-related quality of life using the Euroqol-5D, an investigation of agreement. Med Care. 2008;46(11):1140-1148.

112. Pickard AS, Knight SJ. Proxy evaluation of health-related quality of life: a conceptual framework for understanding multiple proxy perspectives. Med Care. 2005;43(5):493.

113. Yach D, Hawkes C, Gould CL, Hofman KJ. The global burden of chronic diseases: overcoming impediments to prevention and control. JAMA. 2004;291(21):2616-2622.

114. Panagioti M, Richardson G, Murray E, et al. Reducing Care Utilisation through Self-management Interventions (RECURSIVE): A Systematic Review and Meta-analysis. Southampton, UK: Queen's Printer and Controller of HMSO; 2014.

115. Russell LB. Preventing chronic disease: an important investment, but don't count on cost savings. Health Aff. 2009;28(1):42-45.

116. Thompson KM, Tebbens RJD. Retrospective cost-effectiveness analyses for polio vaccination in the United States. Risk Anal. 2006;26(6):1423-1440.

117. Johannesson M. At what coronary risk level is it cost-effective to initiate cholesterol lowering drug treatment in primary prevention? Eur Heart J. 2001;22(11):919-925.

118. Raftery JP, Yao GL, Murchie P, Campbell NC, Ritchie LD. Cost effectiveness of nurse led secondary prevention clinics for coronary heart disease in primary care: follow up of a randomised controlled trial. BMJ. 2005;330(7493):707.

119. Hankey GJ, Warlow CP. Treatment and secondary prevention of stroke: evidence, costs, and effects on individuals and populations. Lancet. 1999;354(9188):1457-1463.

120. Gaspoz JM, Coxson PG, Goldman PA, et al. Cost effectiveness of aspirin, clopidogrel, or both for secondary prevention of coronary heart disease. N Engl J Med. 2002;346(23):1800-1806.

121. Fagan K, Zhao EY, Horsfall L, et al. Burden of decompensated cirrhosis and ascites on hospital services in a tertiary care facility: time for change? Intern Med J. 2014;44(9):865-872.

122. Price E, Baker R, Krause J, Keen C. Organisation of services for people with cardiovascular disorders in primary care: transfer to primary care or to specialist-generalist multidisciplinary teams? BMC Fam Pract. 2014; $15: 158$.

123. Sanmuganathan $P$, Ghahramani P, Jackson P, Wallis E, Ramsay L. Aspirin for primary prevention of coronary heart disease: safety and absolute benefit related to coronary risk derived from meta-analysis of randomised trials. Heart. 2001;85(3):265-271.
124. Nakamura H, Arakawa $\mathrm{K}$, Itakura $\mathrm{H}$, et al. Primary prevention of cardiovascular disease with pravastatin in Japan (MEGA Study): a prospective randomised controlled trial. Lancet. 2006;368(9542): 1155-1163.

125. Rembold CM. Number needed to screen: development of a statistic for disease screening. BMJ. 1998;317(7154):307-312.

126. Caro J, Klittich W, McGuire A, et al. The West of Scotland coronary prevention study: economic benefit analysis of primary prevention with pravastatin. BMJ. 1997;315(7122):1577-1582.

127. Ridker PM, Rifai N, Clearfield M, et al. Measurement of C-reactive protein for the targeting of statin therapy in the primary prevention of acute coronary events. $N$ Engl J Med. 2001;344(26):1959-1965.

128. McPhail SM, Schippers M, Maher CA, Marshall AL. Patient preferences for receiving remote-communication support for lifestyle physical activity behaviour change: the perspective of patients with musculoskeletal disorders from three hospital services. BioMed Res Int. 2015;2015:390352.

129. Dranove D. Pricing by non-profit institutions. The case of hospital cost-shifting. J Health Econ. 1988;7(1):47-57.

130. Wu VY. Hospital cost shifting revisited: new evidence from the balanced budget act of 1997. Int J Health Care Finance Econ. 2010;10(1):61-83.

131. Fuchs VR. Cost shifting does not reduce the cost of health care. JAMA. 2009;302(9):999-1000.

132. Frakt AB. How much do hospitals cost shift? A review of the evidence. Milbank Q. 2011;89(1):90-130.

133. Murray R. Setting hospital rates to control costs and boost quality: the Maryland experience. Health Aff. 2009;28(5):1395-1405.

134. Duckett S. The Australian Health Care System. New York, NY: Oxford University Press; 2004.

135. Schoen C, Osborn R, Squires D, Doty M, Pierson R, Applebaum S. New 2011 survey of patients with complex care needs in eleven countries finds that care is often poorly coordinated. Health Aff. 2011; 30(12):2437-2448

136. Wennberg JE, Fisher ES, Stukel TA, Skinner JS, Sharp SM, Bronner KK. Use of hospitals, physician visits, and hospice care during last six months of life among cohorts loyal to highly respected hospitals in the United States. BMJ. 2004;328(7440):607.

137. Chan R, Webster J. End-of-life care pathways for improving outcomes in caring for the dying. Cochrane Database Syst Rev. 2010;1:CD008006.

138. Hogan C, Lunney J, Gabel J, Lynn J. Medicare beneficiaries' costs of care in the last year of life. Health Aff. 2001;20(4):188-195.

139. Frost DW, Cook DJ, Heyland DK, Fowler RA. Patient and healthcare professional factors influencing end-of-life decisionmaking during critical illness: a systematic review. Crit Care Med. 2011;39(5):1174-1189.

140. Candrilli SD, Meyers JL, Boye K, Bae JP. Health care resource utilization and costs during episodes of care for type 2 diabetes mellitusrelated comorbidities. J Diabetes Complicat. 2015;29(4):529-533.

141. Tonelli M, Wiebe N, Guthrie B, et al. Comorbidity as a driver of adverse outcomes in people with chronic kidney disease. Kidney Int. 2015;88(4):859-866.

142. May CR, Eton DT, Boehmer K, et al. Rethinking the patient: using Burden of Treatment Theory to understand the changing dynamics of illness. BMC Health Serv Res. 2014;14(1):1-11.

143. Shippee ND, Shah ND, May CR, Mair FS, Montori VM. Cumulative complexity: a functional, patient-centered model of patient complexity can improve research and practice. J Clin Epidemiol. 2012; 65(10):1041-1051.

144. Glasgow RE, Chambers D. Developing robust, sustainable, implementation systems using rigorous, rapid and relevant science. Clin Transl Sci. 2012;5(1):48-55.

145. Parchman M, Scoglio C, Schumm P. Understanding the implementation of evidence-based care: a structural network approach. Implement Sci. 2011;6(1):14. 
Risk Management and Healthcare Policy is an international, peer-reviewed, open access journal focusing on all aspects of public health, policy, and preventative measures to promote good health and improve morbidity and mortality in the population. The journal welcomes submitted papers covering original research, basic science, clinical and epidemiological studies, reviews and evaluations, guidelines, expert opinion and commentary, case reports and extended reports. The manuscript management system is completely online and includes a very quick and fair peerreview system, which is all easy to use. Visit http://www.dovepress.com/ testimonials.php to read real quotes from published authors.

Submit your manuscript here: https://www.dovepress.com/risk-management-and-healthcare-policy-journal 